\title{
A METONÍMIA SEGUNDO OS GRAMÁTICOS E RÉTORES LATINOS ${ }^{1}$
}

\author{
Lya Serignolli* \\ Recebido em: 24/01/2018 \\ Aprovado em: 12/06/2018
}

RESUMO: Este artigo tem por fim discutir os principais aspectos da metonímia de acordo com os gramáticos e rétores latinos. Primeiramente, serão elencadas definições desse tropo (ou figura) segundo rétores e gramáticos latinos, tais como o anônimo da Retórica a Herênio, Cícero, Quintiliano, Donato, Festo e Isidoro de Sevilha. Em segundo lugar, serão observadas as diversas espécies de metonímia encontradas em textos antigos. Por fim, serão investigadas as relações entre a metonímia e outras figuras e tropos, especialmente a metáfora, a sinédoque e a catacrese.

PALAVRAS-CHAVE: Metonímia; immutatio; tropos; figuras; gramática; retórica.

\section{METONYMY ACCORDING TO LATIN GRAMMARLANS AND RHETORICLANS}

* Doutora em

Letras Clássicas, Universidade de São Paulo. Pós-

Doutorado em

Letras Clássicas

(em andamento), Universidade de São

Paulo.

lya.serignolli@usp.br

\begin{abstract}
This article aims to discuss the main aspects of metonymy according to Latin grammarians and rhetoricians. Firstly, definitions of this trope (or figure) according to Latin rhetoricians and grammarians, such as the unknown author of the Rhetorica Ad Herennium, Cicero, Quintilian, Donatus, Festus and Isidore of Seville, will be gathered. Secondly, different types of metonymy found in ancient texts will be

\footnotetext{
${ }^{1}$ Meus agradecimentos aos pareceristas anônimos da Classica pelas sugestões para o aperfeiçoamento deste artigo; ao Professor Dr. Marcos Martinho dos Santos, que ministrou o curso de pós-graduação "Lições sobre Metaplasmos, Figuras e Tropos de Gramáticos e Rétores Gregos e Latinos”, na Faculdade de Filosofia, Letras e Ciências Humanas da Universidade de São Paulo, do qual participei durante meu doutorado e que resultou neste artigo; e à Fundação de Amparo à Pesquisa do Estado de São Paulo (FAPESP) pelo financiamento desta pesquisa.
} 
observed. Finally, relations between metonymy and other figures and tropes, especially metaphor, synecdoche and catachresis will be investigated.

KEYWORDS: Metonymy; immutatio; tropes; figures; gramar; rhetoric.

\section{INTRODUÇÃO}

$\mathrm{S}$

egundo os gramáticos e rétores latinos, a metonímia, em linhas gerais, consiste no emprego de uma palavra, não em seu sentido próprio, mas em outro com o qual ela possua alguma relação de contiguidade. ${ }^{2}$ Assim, na metonímia ocorre uma transferência de sentido por meio da substituição de palavras adjuntas, próximas ou indissociáveis. As relações entre a palavra empregada metonimicamente e o significado sugerido podem ser de diversas espécies, entre elas: inventor-invenção, proprietário-propriedade, instrumentopossessor, conteúdo-continente, causa-efeito, abstrato-concreto, símbolo-fenômeno social, gênero-espécie, parte-todo e número.

Este artigo tem por fim discutir os principais aspectos da metonímia de acordo com os gramáticos e rétores latinos. Primeiramente serão observadas as definições deste tropo (ou figura) ${ }^{3}$ apresentadas por autores latinos, mais especificamente: o anônimo da Retórica a Herênio, Cícero, Quintiliano, Donato, Festo e Isidoro de Sevilha. Em segundo lugar, a título de exemplo, serão elencadas as diversas espécies de metonímia utilizadas por poetas, como Virgilio e Horácio, e citadas por rétores e gramáticos latinos. Por fim, serão investigadas as relações entre a metonímia e outras figuras e tropos, como a metáfora, a sinédoque e a catacrese.

Esta investigação é relevante e necessária, especialmente para a área de Letras Clássicas, pois há um extenso corpus de definições de metonímia segundo os rétores e gramáticos latinos, e, no entanto, a despeito das inúmeras discussões e teorias contemporâneas concernentes à metonímia, são raros os textos que abordam este tema especificamente em fontes antigas.

\section{Definições}

Os rétores e oradores definem a metonímia por meio da explicação etimológica do termo ou citando exemplos das diversas espécies de relações metonímicas. Nas várias definições de metonímia (também chamada traductio, immutatio, denominatio ou transnominatio) é recorrente a ideia de substituição de um nome por outro. Tal aspecto está na etimologia

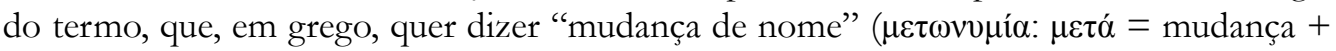

\footnotetext{
${ }^{2}$ Para as definições de metonímia, cf.: Cic., De Or. 3.167; Her. 4.43.1; Quint., Inst. Or. 8.6.23.1; Donato, De tropis, p. 1776 P.; Isid., Orig. 1.37.8.

${ }^{3} \mathrm{O}$ anônimo da Retórica a Herênio (Her., 4.42) inclui a metonímia entre outras nove figuras de palavras (exornationes verborum) que se distinguem por se desprenderem de seu sentido próprio para outro, conferindo graça (venustas) ao discurso.
} 
ővo $\mu \alpha=$ nome). Quintiliano está entre os autores que se referem à etimologia para definir a metonímia:

(8.6.23.1) Nec procul ab hoc genere discedit $\mu \varepsilon \tau \omega v v \mu$ í $\alpha$, quae est nominis pro nomine positio, [cuius uis est pro eo quod dicitur causam propter quam dicitur ponere] sed, ut ait Cicero, hypallagen rhetores dicunt. Haec inuentas ab inuentore et (8.6.23.5) subiectas res ab optinentibus significat, ut 'Cererem corruptam undis', et 'receptus terra Neptunus classes aquilonibus arcet'. (8.6.24.1) Quod fit retrorsum durius. Refert autem in quantum hic tropos oratorem sequatur. Nam ut 'Vulcanum' pro igne uulgo audimus et 'uario Marte pugnatum' eruditus est sermo et 'Venerem' quam coitum dixisse magis decet, ita 'Liberum (8.6.24.5) et Cererem' pro uino et pane licentius quam ut fori seueritas ferat. Sicut ex eo quod < continet id quod $>$ continetur: usus recipit 'bene moratas urbes' et 'poculum epotum' et 'saeculum (8.6.25.1) felix', at id quod contra est raro audeat nisi poeta: 'iam proximus ardet | Vcalegon.' Nisi forte hoc potius est a possessore quod possidetur, ut 'hominem deuorari', cuius patrimonium consumatur: quo (8.6.26.1) modo fiunt innumerabiles species. Huius enim sunt generis cum 'ab Hannibale' caesa [et apud tragicos aegialeo] apud Cannas sexaginta milia dicimus, et carmina Vergili 'Vergilium', 'uenisse' commeatus qui adferantur, 'sacrilegium' (8.6.26.5) deprehensum, non sacrilegum, 'armorum' scientiam habere, (8.6.27.1) non artis. Illud quoque et poetis et oratoribus frequens, quo id quod efficit ex eo quod efficitur ostendimus. Nam et carminum auctores 'pallida mors aequo pulsat pede pauperum tabernas', (8.6.27.5) et 'pallentesque habitant morbi tristisque senectus' et orator 'praecipitem iram', 'hilarem adulescentiam', 'segne otium' dicet. ${ }^{4}$

(8.6.23.1) Não se distancia desse gênero ${ }^{5}$ a metonímia, que é a substituição de um nome por outro, [cuja força consiste em substituir algo que queremos dizer pela causa porque se diz] ${ }^{6}$; e, como diz Cícero, os rétores a chamam hipálage. (8.6.23.5) Esta é usada para substituir invenção pelo inventor ou a coisa possuída pelo possessor, como em: "Ceres deteriorada pelas ondas" ; e em: "Netuno, admitido à terra, as frotas protege do Aquilão". 8 (8.6.24.1) Porém, na forma contrária, resulta em maior dureza. Questiona-se, pois, em que medida o orador deve empregar estes tropos. Uma vez que, embora seja corriqueiro o uso de "Vulcano" para fogo, e seja erudita a expressão "combater com

\footnotetext{
${ }^{4}$ Quint., Inst. Or. 8.6.23-27.

${ }^{5}$ Sinédoque.

${ }^{6} \mathrm{~A}$ frase em latim, entre chaves, refere-se à operação de substituição da causa pelo efeito, cf. Butler (1996, 312), in: Quintilian. Institutio Oratoria VII-IX. Cambridge: Harvard University Press.

${ }^{7}$ Virg., Aen. 1.177.

${ }^{8}$ Hor., A. P. 63.
}

Classica, v. 31, n. 1, p. 89-110, 2018 
Marte adverso", e seja mais decente dizer "Vênus" do que coito, seria, no entanto, mais licencioso do que convém à severidade dos tribunais dizer "Líber (8.6.24.5) e Ceres" para referir-se ao vinho e ao pão. Do mesmo modo, o uso nos permite substituir o conteúdo pelo continente: "cidades de bons costumes", "beber um copo inteiro" e (8.6.25.1) "século feliz"; e raramente alguém ousaria utilizar a forma contrária, salvo um poeta: “já, próximo, arde Ucalegonte". ${ }^{9}$ Entretanto, talvez seja mais permissível tomar a posse pelo possessor, como quando dizemos que "está sendo devorado" um homem cujo patrimônio esteja sendo consumido; desse gênero há inúmeras espécies, (8.6.26.1) por exemplo, quando dizemos que sessenta mil homens foram mortos "por Aníbal" em Canas [e, entre os trágicos, "por Egialeu”]; e "Virgílio" em referência aos poemas de Virgílio; ou que "chegaram" os suprimentos que foram trazidos; ou que um "sacrilégio" foi descoberto (8.6.26.5), e não um sacrílego; ou que alguém é conhecedor de "armas", e não da arte das armas. (8.6.27.1) É frequente também entre os poetas e oradores indicar a causa a partir do efeito. Assim, os poetas dirão: "a pálida morte, com pé igual, chuta as choupanas dos pobres", ${ }^{10}$ (8.6.27.5) e "as pálidas doenças habitam na triste senectude"; ${ }^{11}$ e o orador dirá: "precipitada ira", "alegre adolescência” e "ócio preguiçoso". ${ }^{2}$

A definição etimológica limita a ocorrência da metonímia à esfera nominal, contudo, como notamos acima, há exemplos em que a transposição de sentido ocorre no verbo, como em: 'uenisse' commeatus qui adferantur, que diz que "chegaram" os suprimentos que foram trazidos. ${ }^{13}$

Donato define metonímia como transnominatio (transnominação), que significa substituição de nomes:

4. Metonymia est [dictio] quaedam veluti transnominatio. Huius multae sunt species. aut enim per id quod continet id quod continetur ostendit, ut «nunc pateras libate Iovi»; aut contra, ut «vina coronant»; aut per inventorem id quod inventum est [ostendit], ut sine Cerere et Libero friget Venus; aut contra, ut vinum precamur, nam hic deus praesens adest. $^{14}$

A metonímia é [figura] como uma transnominação. Dela há muitas espécies, tais como: mostrar conteúdo pelo continente, como em: "agora oferecei as páteras a Júpiter", ou a forma contrária, como em: "coroam-

\footnotetext{
${ }^{9}$ Virg., Aen. 2.311.

${ }^{10}$ Hor., C. 1.4.13.

${ }^{11}$ Virg., Aen. 6.275.

${ }^{12}$ Todas as traduções neste artigo são de minha autoria.

${ }^{13}$ Quint., Inst. Or. 8.6.26.1. Sobre o aspecto etimológico nas definições de metonímia, cf. Lausberg (2003, Tomo II, 71).

${ }^{14}$ Donato, De tropis, p. 1776 P.
}

Classica, v. 31, n. 1, p. 89-110, 2018 
se os vinhos"; e [mostrar] o inventor para significar a invenção, como em: "Sem Ceres e Líber, Vênus é fria"; ou na forma contrária, como em: suplicamos ao vinho, pois este deus se faz presente.

Os termos latinos traductio e immutatio, usados por Cícero no De Oratore, dimensionam, respectivamente, as operações de transferência e substituição características da metonímia:

(3.167.5) Ne illa quidem traductio atque immutatio in verbo quandam fabricationem habet [sed in oratione]: Africa terribili tremit horrida terra tumultu; [pro Afris est sumpta Africa,] neque factum est verbum, ut (3.167.10) "mare saxifragis undis"; neque translatum, ut "mollitur mare"; sed ornandi causa proprium proprio commutatum: desine, Roma, tuos hostis.... <et> testes sunt campi magni.... (3.167.15) Gravis est modus in ornatu orationis et saepe sumendus; ex quo genere haec sunt, Martem belli esse communem, Cererem pro frugibus, Liberum appellare pro vino, Neptunum pro mari, curiam pro senatu, campum pro comitiis, (3.168.1) togam pro pace, arma ac tela pro bello; quo item in genere et virtutes et vitia pro ipsis, in quibus illa sunt, appellantur: "luxuries quam in domum inrupit," et "quo avaritia penetravit"; aut "fides valuit, iustitia confecit." Videtis profecto (3.168.5) genus hoc totum, cum inflexo immutatoque verbo res eadem enuntiatur ornatius; cui sunt finitima illa minus ornata, sed tamen non ignoranda, cum intellegi volumus aliquid aut ex parte totum, ut pro aedificiis cum parietes aut tecta dicimus; aut ex toto partem, ut cum unam (3.168.10) turmam equitatum populi Romani dicimus; aut ex uno pluris: at Romanus homo, tamenetsi res bene gesta est corde suo trepidat; aut cum ex pluribus intellegitur unum: (3.168.15) nos sumus Romani, qui fuimus ante Rudini; aut quocumque modo, non ut dictum est, in eo genere (3.169.1) intellegitur, sed ut sensum est. Abutimur saepe etiam verbo non tam eleganter quam in transferendo, sed etiam si licentius, tamen interdum non impudenter; ut cum grandem orationem pro longa, minutum animum pro parvo dicimus. (3.169.5) Verum illa videtisne esse non verbi, sed orationis, quae ex pluribus, ut exposui, translationibus conexa sunt? Haec autem, quae aut immutata esse dixi aut aliter intellegenda (3.170.1) ac dicerentur, sunt translata quodam modo. ${ }^{15}$

(3.167.5) Tampouco a metonímia, ou substituição, envolve certa inovação na palavra [mas no discurso]: A selvagem África treme com terrível tumulto [África é utilizada em substituição a africanos]; nem uma palavra é inventada, como em: "o mar com suas ondas quebra-pedras"; 16

\footnotetext{
${ }^{15}$ Cic., De Or. 3.167-170.

${ }^{16}$ Uma tradução mais interpretativa da frase "mare saxifragis undis" poderia ser: "o mar com suas ondas que se quebram contra as pedras", porém não teria a ênfase dada por Cícero à palavra composta saxifragus como neologismo.
}

Classica, v. 31, n. 1, p. 89-110, 2018 
e nem é trasladada, como em (3.167.10): “o mar se suaviza”; mas, com o objetivo de ornamentar, substitui-se um nome próprio por outro, como em: Cessa, Roma, [de temer] teus inimigos .... <e $>$ os Grandes Campos são testemunhas .... ${ }^{17}$ (3.167.15) Este procedimento é eficaz para ornar o discurso, e deve ser adotado com frequência; deste gênero originaram-se a expressão a imparcialidade de Marte na guerra e o uso dos termos Ceres em referência aos cereais, Líber ao vinho, Netuno ao mar, cúria ao senado, assembleia do povo às eleições, (3.168.1) toga à paz, arma e lança à guerra; neste mesmo gênero inclui-se o uso dos nomes das virtudes e dos vícios em referência àqueles que as possuem: "casa invadida pelo excesso", e "onde a cobiça penetrou"; ou "a lealdade prevaleceu”, "a justiça foi feita”. Nota-se que (3.168.5) em todo esse gênero de expressões o mesmo significado é obtido com maior elegância por meio de modificação ou alteração de palavra. A esta, assemelha-se aquela ${ }^{18}$ menos elegante, mas que, no entanto, não deve ser ignorada, empregada quando desejamos que se entenda a parte pelo todo, como quando dizemos paredes e teto para nos referirmos à casa; ou o todo pela parte, como quando dizemos a cavalaria romana em referência (3.168.10) a um batalhão; ou quando nos referimos a um dando a entender muitos, como em: Mas o coração do homem romano palpita, ainda que a luta tenha sido bem travada; ou quando a partir de muitos damos a entender um, como em: (3.168.15) Nós, que antes éramos rudinos, agora somos romanos. Ou qualquer outro modo em que a palavra seja utilizada, (3.169.1) não em sentido literal, mas sugerido. Também, frequentemente, utilizamos uma palavra ${ }^{19}$ de modo não tão elegante quanto em metáforas, tal uso, apesar de mais livre, no entanto, por vezes não é sem escrúpulos; como quando dizemos discurso de grandes proporções em vez de longo, e uma mente diminuta em vez de pequena. (3.169.5) Mas aquela, ${ }^{20}$ como expliquei, que se compõe de uma série de termos transladados, na verdade, não lhes parece ser mais um problema de discurso do que de palavras? Estas, no entanto, que consistem em palavra substituída, como eu disse, ou com outro significado que não o literal, (3.170.1) são de algum modo metáforas.

\footnotetext{
${ }^{17}$ A passagem desine Roma tuos hostis... testes sunt Campi Magni, foi provavelmente extraída de Ênio, Cipião; cf. Q. Ennius, Varia 6 e 8 (Ennianae Poesis Reliquiae, ed. J. Vahlen, 1928). Campi Magni (Grandes Campos ou Grandes Planícies): localidade na África, na região da atual Tunísia, onde Cipião Africano, em 203 a.C. (final da Segunda Guerra Púnica), travou uma batalha contra Asdrúbal Giscão (comandante cartaginês) e Sífax (rei númida); cf. Tito Lívio, Ab Urbe Condita 30.8. As substituições nessa passagem ocorrem de tal modo que "Roma" substitui "romanos"; e "os Grandes Campos", "a África".

${ }^{18}$ Deduzimos, a partir dos exemplos citados, que Cícero se refere à sinédoque.

${ }^{19}$ Isto é, a metonímia.

${ }^{20}$ Alegoria. Para a definição de alegoria segundo Cícero, cf. De Or. 3.166-167.
} 
Na Retórica a Herênio, a metonímia é chamada denominatio:

(4.43.1) Denominatio est, quae ab rebus propinquis et finitimis trahit orationem, qua possit intellegi res, quae non suo vocabulo sit appellata. Id aut ab inventore conficitur, ut si quis, de Tarpeio (4.43.5) loquens, eum Capitolinum nominet, aut invento, ut si quis pro Libero vinum, pro Cerere frugem appellet; aut invento, ut si quis pro Libero vinum, pro Cerere frugem appellet; ...; aut instrumento dominum, ut si quis Macedones appellarit hoc modo: 'Non tam cito sarisae Graeciae (4.43.10) potitae sunt,' aut idem Gallos significans: 'nec tam facile ex Italia mat<e >ris 'Transalpina depulsa est;' aut id, quod fit, ab eo, qui facit, ut si quis, cum bello velit ostendere aliquid quempiam fecisse, dicat: 'Mars istuc te facere necessario coegit;' (4.43.15) aut si, quod facit, ab eo, quod fit, ut cum desidiosam artem dicimus, quia desidiosos facit, et frigus pigrum, quia pigros efficit. Ab eo, quod continet, id, quod continetur, hoc modo denominabitur: 'Armis Italia non potest vinci nec (4.43.20) Graecia disciplinis' - nam hic pro Graecis et Italis, quae continent, notata sunt - ab eo, quod continetur, id, quod continet, ut si quis aurum aut argentum aut ebur nominet, cum divitias velit nominare. (4.43.25) Harum omnium denominationum magis in praecipiendo divisio, quam in quaerendo difficilis inventio est, ideo quod plena consuetudo est non modo poëtarum et oratorum, sed etiam cottidiani sermonis huiusmodi denominationum. ${ }^{21}$

(4.43.1) Metonímia ocorre quando se extrai o significado de coisas próximas ou associadas, de modo a sugerir determinada coisa sem utilizar o termo próprio. Pode-se obtê-la substituindo-se o inventor [pela invenção], como alguém que se referindo a Tarpeio (4.43.5) dissesse o Capitolino; ou substituindo-se a invenção [pelo inventor], como dizer Líber para referir-se ao vinho, ou Ceres para cereal; ou mencionando-se o instrumento no lugar do seu possessor, como se alguém se referisse aos Macedônios deste modo: "Não tão rápido as sarissas ${ }^{22}$ apossaramse da Grécia"; (4.43.10) e do mesmo modo, referindo-se ao gauleses, dizer: "nem a lança transalpina foi tão facilmente expulsa da Itália"; ou substituir a causa pelo efeito, como se alguém, querendo demonstrar que certa pessoa fez algo na guerra, dissesse: "Marte obrigou-te a fazer isso"; (4.43.15) ou o efeito pela causa, quando dizemos que uma arte é ociosa, porque ela torna as pessoas ociosas, ou que o frio é preguiçoso, porque ele causa preguiça. E quando se denomina o conteúdo pelo continente, do seguinte modo: "Não é possível vencer a Itália na guerra, (4.43.20) nem a Grécia nos estudos" - pois, aqui, no lugar de gregos e italianos, mencionam-se os lugares a que estes pertencem. O continente

${ }^{21}$ Ad Her. 4.43.1-25.

${ }^{22}$ Lanças dos macedônios.

Classica, v. 31, n. 1, p. 89-110, 2018 
é designado pelo conteúdo, como quando alguém, querendo referir-se à riqueza, disser ouro, prata ou marfim. (4.43.25) É mais difícil ensinar as distinções entre todas essas metonímias do que encontrá-las, pois metonímias desta espécie são de uso corrente não só entre os poetas, mas também na fala cotidiana.

Isidoro de Sevilha, tal como Donato, define a metonímia como transnominatio:

[8] Metonymia, transnominatio ab alia significatione ad aliam proximitatem translata. Fit autem multis modis. Aut enim per id, quod continet, id, quod continetur, ostendit, ut "theatra plaudunt" "prata mugiunt" dum illic homines plaudunt, hic boves mugiant; aut contra per id, quod continetur, id, quod continet, ut (Virg., Aen. 2,311): Iam proximus ardet Vcalegon; dum non ille, sed domus eius arderet. [9] Item per inventorem id, quod inventum est, ut (Ter., Eun. 732): Sine Cerere et Libero friget Venus; et (Virg., Aen. 9.76): Conmixtam Vulcanus mittit ad astra favillam. Vult enim per Cererem frumenti inventricem intellegere panem, per Liberum inventorem vitis vinum, per Venerem libidinem, per Vulcanum ignem. At contra per inventum inventorem demonstrat, ut (Plaut., frag. 159): Vinum precamur, pro Libero, qui vinum apud Graecos invenit. [10] Item per efficientem, id quod efficitur, sicut "pigrum frigus" quod pigros homines faciat, et "timor pallidus" eo quod pallidos homines reddat. At contra per id quod efficitur, efficiens, ut: Iungit equos auri genitor spumantiaque addit frena feris. "Spumantia frena"23 dixit, cum utique non ipsa faciant spumas, sed equus, qui ea gerit, spumis conspargat infusis. ${ }^{24}$

[8] Metonímia é uma transnominação em que um significado é transferido para outro em relação de contiguidade. Ela ocorre, pois, de muitas maneiras, tais como: mostrar o conteúdo pelo continente, como em: "o teatro aplaude", "os campos mugem", enquanto que no primeiro exemplo os homens aplaudem, e no segundo as vacas mugem. $\mathrm{Na}$ forma contrária, mostra o continente pelo conteúdo, como em: já, próximo, arde Ucalegonte, ${ }^{25}$ enquanto que, não Ucalegonte, mas sua casa ardia em chamas. [9] Também, por meio do inventor, indica-se a invenção, como em: Sem Ceres e Líber, Vênus é fria; e em: Vulcano lança fagulhas misturadas às estrelas. Pois, ao dizer Ceres, inventora dos grãos, ele se refere ao pão; ao dizer Líber, inventor da videira, quer dizer vinho; para o desejo diz Vênus e para o fogo Vulcano. Na forma contrária, mostra a invenção no lugar do inventor, como em: Rogamos ao vinho, no lugar de Líber, que, de acordo com os gregos, inventou o vinho. [10] Também,

\footnotetext{
${ }^{23}$ Virg. Aen. 5.817.

${ }^{24}$ Isid., Orig. 1.37.8-10.

${ }^{25}$ Virg., Aen. 2.311.
} 
mostra o efeito pela causa, como em: "frio preguiçoso", porque ele torna as pessoas preguiçosas, e "temor pálido", porque ele torna as pessoas pálidas. Na forma contrária, expressa a causa pelo efeito, como em: "O pai atrela as rédeas nos bravios cavalos e coloca-lhes na boca os espumantes freios de ouro". Ele disse “espumantes freios”, embora certamente eles mesmos não façam espuma, mas o cavalo que os utiliza os molha com a saliva derramada.

Festo, por sua vez, não se vale da etimologia do termo para explicar a metonímia, definindo-a simplesmente como um tropo:

Metonymia est tropos, cum ab eo quod continet, significatur id, quod continetur, aut superior $<\mathrm{r}>\mathrm{es}$ inferiore, et inferior superiore. Quae continet, quod continetur: ut Ennius (153.25) cum ait: "Africa terribili tremis horrida terra tumultu." Ab eo quod continetur id quod continet; ut cum dicitur: "epota amphora vini." A superiore re inferior, ut Ennius: "cum magno strepitu Volcanum ventus vegebat." Ab inferiore superior, (153.30) ut: "persuasit animo vinum, deus qui multo est maximus."26

Metonímia é um tropo em que se indica conteúdo pelo continente, ou o superior pelo inferior e o inferior pelo superior. Pelo continente, o conteúdo, tal como quando Ênio diz: "Selvagem África, tu tremes com terrível tumulto"; e, pelo conteúdo, o continente, como quando se diz: "depois de beber uma ânfora de vinho até o fim". ${ }^{27}$ Pelo superior indicase o inferior, como em Ênio: "com grande estrondo o vento impelia Vulcano"; e, pelo inferior, o superior, como em: "o vinho, deus que é de longe o maior, persuade a mente."

Tropo é torneio, desvio de referência, e pressupõe a percepção da transferência. Transferindo-se para o que é impróprio, troca-se a referência pela transferência. A alteração no tropo não é fonética (sintética) e nem sintática, mas semântica, referencial e, como ensina Quintiliano, é sempre virtuosa (cum virtute):

Tropos est uerbi uel sermonis a propria significatione in aliam cum nirtute mutatio. ${ }^{28}$

Tropo é a modificação virtuosa de palavra ou de discurso de seu significado próprio para outro.

\footnotetext{
${ }^{26}$ Festo, De Verborum Significatione 153.22-31.

${ }^{27} \mathrm{O}$ exemplo citado, na verdade, condiz com a relação contrária, de substituição do conteúdo (vinho) pelo continente (ânfora), de modo semelhante a outros exemplos citados por outros autores, como: Quintiliano, Inst. Or. 8.6.24: poculum epotum (beber um copo inteiro); e Donato, De Tropis, p. 1776 P: nunc pateras libate Iovi (agora oferecei páteras a Júpiter).

${ }^{28}$ Quint., Inst. Or. 8.6.1.
}

Classica, v. 31, n. 1, p. 89-110, 2018 
Como sugere Lausberg, a immutatio (modificação de palavra) por si só constitui um vício e somente se justifica mediante uma função especial..$^{29}$ Donato aponta duas razões para o uso dos tropos, a necessidade ou o ornato:

Tropus est dictio translata a propria significatione ad non proprium similitudinem ornatus necessitatisve causa. ${ }^{30}$

Tropo é palavra transladada do sentido próprio para outro não próprio semelhante, em razão do ornato ou da necessidade.

A metonímia, como tropo, se estabelece por meio de relações de contiguidade entre palavras, das quais observaremos as principais espécies.

\section{RELAÇÕES METONÍMICAS}

\subsection{Causa-efeito}

Na relação metonímica, há uma força ou agente causador que produz um resultado, efeito ou consequência. Segundo Quintiliano, é frequente entre os poetas e oradores mostrar a causa pela consequência. ${ }^{31}$ Cícero diz que o sentido da metonímia é depreendido de algo consequente (res consequens). ${ }^{32}$ A relação de causa-efeito pode ser constituída por pessoa ou por coisa, e assim ela entrelaça-se a outras espécies de metonímia que se desdobram a partir da relação inventor-invenção, seja pela substituição do autor pela obra, do proprietário pela propriedade, do instrumento pelo possessor ou das divindades por seus atributos. ${ }^{33}$

\section{INVENTOR-INVENÇÃo}

De acordo com Arata, da relação inventor-invenção resulta o maior número de metonímias entre os autores gregos. ${ }^{34}$ Entre os latinos, do mesmo modo, esta espécie é frequentemente mencionada nas explicações dos gramáticos e rétores e utilizada por poetas e oradores.

\section{a. autor-obra}

Observa-se, por exemplo, substituição do autor pela obra no exemplo citado por Quintiliano: carmina Vergili 'Vergilium' ("Virgílio" em referência aos poemas de Virgílio). ${ }^{35}$

\footnotetext{
${ }^{29}$ Para immutatio como vício, cf. Lausberg (2003, Tomo II, p. 57-58 e 65)

${ }^{30}$ Donato, De Tropis p. 1775 P.

${ }^{31}$ Quint., Inst. Or. 8.6.27.

${ }^{32}$ Cic., Or. 92.

${ }^{33}$ Lausberg (2004, p. 159-160).

${ }^{34}$ Arata (2005, p. 61).

${ }^{35}$ Quint., Inst. Or. 8.6.26.
} 


\section{b. proprietário-propriedade}

Como exemplos da metonímia decorrente da relação proprietário-propriedade, podemos citar este fornecido por Quintiliano: 'hominem deuorari', cuius patrimonium consumatur ("está sendo devorado" um homem cujo patrimônio esteja sendo consumido), bem como esta passagem da Eneida de Virgílio: iam proximus ardet V calegon (já, próximo, arde Ucalegonte), ${ }^{37}$ em que $V$ calegon refere-se a domus Ucalegonis (a casa de Ucalegonte). Ucalegonte é um personagem da Ilíada, ${ }^{38}$ da corte de Príamo, cuja morada incendiada representa a proximidade da ruína de Príamo no incêndio da queda de Troia.

\section{c. instrumento-possessor}

$\mathrm{Na}$ Retórica a Herênio, são citados dois exemplos de substituição do instrumento pelo possessor: Non tam cito sarisae Graeciae potitae sunt (Não tão rápido as sarissas apossaram-se da Grécia), em que sarisae, ou as lanças dos Macedônios, está no lugar de Macedônios; e: nec tam facile ex Italia mat $<p>$ ris Transalpina depulsa est (nem a lança transalpina foi tão facilmente expulsa da Itália), em que materis Transalpina, ou a lança dos gauleses, está no lugar de gauleses. ${ }^{39}$

\section{d. divindades-atributos}

No De Natura Deorum, de Cícero, é mencionado o uso dos nomes de deuses em substituição às suas invenções ou atributos:

itaque tum illud quod erat a deo natum nomine ipsius dei nuncupabant, ut cum fruges Cererem appellamus vinum autem Liberum, ex quo illud Terenti "sine Cerere et Libero friget Venus". ${ }^{40}$

Assim, aquilo que era inventado por um deus recebia o seu nome, como quando dizemos Ceres para os grãos e Líber para o vinho, tal como em Terêncio: "Sem Ceres e Líber, Vênus é fria".

Essa mesma relação de substituição pode ser observada nos seguintes versos de Horácio:

\section{tu sapientium/ curas et arcanum iocoso/ consilium retegis Lyaeo ${ }^{41}$}

Tu descobres as aflições dos sábios e seu conhecimento secreto com o auxílio do jocoso Lieu.

\footnotetext{
${ }^{36}$ Quint., Inst. Or. 8.6.25-26.

${ }^{37}$ Virg., Aen. 2.311.

${ }^{38}$ Hom., Il. 3.148.

${ }^{39}$ Her. 4.43.

${ }^{40}$ Cic., N. D. 2.60-61.

${ }^{41}$ Hor., C. 3.21.14-16.

Classica, v. 31, n. 1, p. 89-110, 2018
} 
Nessa passagem, Lyaeus, um dos nomes de Baco, inventor da videira, substitui o vinho. Nota-se também uma relação de causa e efeito entre o adjetivo iocosus e Lyaeus, porque o vinho, invenção de Lieu, torna iocusus (jocoso, divertido, alegre) aquele que o consome.

Os gramáticos e rétores citam inúmeros exemplos do uso desta espécie de metonímia. Quintiliano menciona um exemplo extraído da Eneida: Cererem corruptam undis (Ceres deteriorada pelas ondas), ${ }^{42} \mathrm{em}$ que Ceres quer dizer trigo. Quintiliano cita também um exemplo extraído da Arte Poética de Horácio: receptus terra Neptunus classes aquilonibus $\operatorname{arcet}$ (Netuno, admitido à terra, as frotas protege do Aquilão) ${ }^{43} \mathrm{em}$ que Netuno refere-se ao mar. Na Retórica a Herênio, é mencionado o uso de Marte para a guerra: Mars istuc te facere necessario coegit (Marte obrigou-te a fazer isso) ${ }^{44}$ Cícero também cita metonímias dessa espécie: Cererem pro frugibus, Liberum appellare pro vino, Neptunum pro mari (Ceres em referência aos cereais, Líber ao vinho, Netuno ao mar). ${ }^{45}$ Para Quintiliano, esta espécie de metonímia, embora corriqueira e por vezes conveniente, em sua maioria não condiz com a severidade da oratória nos tribunais. ${ }^{46}$ Os poetas latinos, por sua vez, adotam frequentemente essa espécie de transposição decorrente da relação entre os nomes dos deuses e suas invenções, tal como observamos nos exemplos citados acima, com Vulcano, Ceres, Marte, Netuno e Baco.

Pode ocorrer também a substituição do inventor pela invenção, como neste fragmento de uma comédia de Plauto: vinum precamur, nam hic deus praesens adest (suplicamos ao vinho, pois este deus se faz presente), em que vinho quer dizer Baco. ${ }^{47}$ Essas formas invertidas são menos comuns e, segundo Quintiliano, mais duras. ${ }^{48}$ Ainda assim, são frequentemente

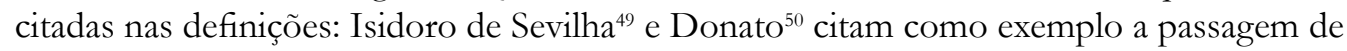
Plauto mencionada acima. Festo fornece o seguinte exemplo: persuasit animo vinum, deus qui multo est maximus (o vinho, deus que é de longe o maior, persuade a mente). ${ }^{51}$

\subsection{Conteúdo-COntinente}

$\mathrm{Na}$ relação conteúdo-continente, o continente pode estar representado por um lugar ou tempo e o conteúdo pode abarcar pessoas ou coisas. ${ }^{52} \mathrm{O}$ conteúdo formado por coisa, na substituição do conteúdo pelo continente, consiste em expressões como: poculum epotum

\footnotetext{
${ }^{42}$ Quint., Inst. Or. 8.6.23.5; Virg. Aen., 1.177. Sérvio, em seu comentário da Eneida (Commentarii in Vergilii Aeneidos libros 1.177.1), considera o uso de Ceres nessa passagem como metonímia para o trigo (CEREREM metonymia pro frumento).

${ }^{43}$ Quint., Inst. Or. 8.6.23; Hor., A. P. 63.

${ }^{44}$ Her. 4.43.

${ }^{45}$ Cic., De Or. 3.167.

${ }^{46}$ Quint., Inst. Or. 8.6.24.

${ }^{47}$ Plauto, Fragmenta inc.38.1.

${ }^{48}$ Quint., Inst. Or. 8.6.24.1.

${ }^{49}$ Isid., Orig. 1.37.9.

${ }^{50}$ Donato, De tropis p. 1776 P.; Isid., Orig. 1.37.9.

${ }^{51}$ Festo, De Verborum Significatione 153.30-31.

${ }^{52}$ Lausberg (2003, p. 73) e (2004, p. 161).
} 
(beber um copo inteiro), ${ }^{53}$ em que poculum refere-se à bebida contida no copo; e: nunc pateras libate Iovi (agora oferecei as páteras a Júpiter), em que paterae são as oferendas dispostas nas páteras. Na forma contrária, do continente pelo conteúdo, temos o exemplo encontrado na Eneida de Virgílio, fornecido por Donato: vina coronant (coroam-se os vinhos), em que vinhos quer dizer as taças ou as crateras de vinho. ${ }^{54}$

O conteúdo formado por pessoa consiste em expressões como: curiam pro senatu (cúria em referência ao senado) e campum pro comitiis (assembleia do povo em referência às eleições). ${ }^{55} \mathrm{O}$ processo de substituição de pessoa por lugar pode ser observado nos exemplos: theatra plaudunt (o teatro aplaude) ${ }^{56}$ e theatra tota reclamant (todo o teatro protesta) $;^{57}$ em ambos os casos, teatro significa o público presente no teatro. Pertence a esta espécie também o exemplo citado na Retórica a Herênio: Armis Italia non potest vinci nec Graecia disciplinis (Não é possível vencer a Itália na guerra, nem a Grécia nos estudos); ${ }^{58}$ e também estes de Quintiliano: bene moratas urbes (cidades de bons costumes), em que cidades refere-se aos habitantes da cidade. Cícero e Festo citam o exemplo de Ênio: Africa terribili tremit horrida terra tumultu (A selvagem África treme com terrível tumulto), em que África refere-se aos habitantes da África. ${ }^{59}$ Pompônio Porfírio, em seu comentário das Epistolas de Horácio, comenta a passagem: iactamus iam pridem omnis te Roma beatum (Toda a Roma há muito tempo te considera feliz $)^{60}$, especificando como metonímia o uso da expressão toda a Roma no lugar de os romanos. ${ }^{61}$ Sérvio, por sua vez, comenta as seguintes passagens da Eneida de Virgílio, destacando metonímias desta mesma espécie: ${ }^{62}$

Arcadas insuetos acies inferre pedestris ut uidit Pallas Latio dare terga sequaci ${ }^{63}$

Quando Palantes viu seus Árcades, desabituados a batalhas campestres, fugirem antes de perseguir o Lácio.

e:

\footnotetext{
${ }^{53}$ Quint., Inst. Or. 8.6.24.

${ }^{54}$ Donato, De Tropis, p. 1776 P; Virg., Aen. 1.724, 7.147.

${ }^{55}$ Cic., De Or. 3.167.

${ }^{56}$ Isid., Orig. 1.37.8.

${ }^{57}$ Cic., De Or. 3.196.

${ }^{58}$ Her. 4.43.

${ }^{59}$ Ênio, An. 9.319; Cic., De Or. 3.167, Or. 93.4-5; Festo, De Verborum Significatione 153.25-26.

${ }^{60}$ Hor., Ep.1.16.18.

${ }^{61}$ Porfírio, Commentum in Horati Epistulas 1.16.18.5-6: Quid est omnis Roma? [Quid est] omnes Roman<i>. Et est figura per metonymiam. (O que significa toda a Roma? Quer dizer “todos os romanos”. Há uma figura por metonímia).

${ }^{62}$ Sérvio, Vergilii Aeneidos Libros 10.365.1: LATIO SEQVACI metonymia pro 'Latinis', ut alibi “invadunt urbem somno vinoque sepultam”. (PERSEGUIR O LÁCIO: metonímia para “os Latinos”, como em outro lugar: "eles invadem a cidade, sepulta no sono e no vinho").

${ }^{63}$ Virg., Aen. 10.364-5.
}

Classica, v. 31, n. 1, p. 89-110, 2018 


\section{inuadunt urbem somno uinoque sepultam ${ }^{64}$}

Eles invadem a cidade, sepulta no sono e no vinho.

Nos dois exemplos ocorre substituição de pessoa por lugar: no primeiro, o Lácio quer dizer os habitantes do Lácio; e no segundo exemplo, cidade refere-se aos habitantes da cidade.

$\mathrm{Na}$ expressão saeculum felix (século feliz), ${ }^{65}$ o tempo referencia os homens e as condições sociais de uma época.

\subsection{Abstrato-Concreto}

A este gênero pertence o uso dos nomes das virtudes e dos vícios em referência àqueles que as possuem, como nos exemplos mencionados por Cicero: "luxuries quam in domum inrupit," et "quo avaritia penetravit"; aut "fides valuit, iustitia confecit" ("casa invadida pelo excesso", e "onde a cobiça penetrou"; ou "a lealdade prevaleceu", "a justiça foi feita"); e por Quintiliano: "sacrilegium" deprehensum, non sacrilegum (um "sacrilégio" foi descoberto, e não um sacrílego). ${ }^{67}$

\subsection{SÍMBOLO-FENÔMENO SOCIAL}

Segundo Lausberg, na implicação de fenômeno e símbolo (signum) sociais, o fundamento para a denominação concreta de um fenômeno social é dado pelo seu símbolo instrumental. ${ }^{68}$ Metonímias desta espécie são mencionadas por Quintiliano: 'armorum' scientiam habere (ser conhecedor de "armas"); $;{ }^{69}$ e também por Cícero: togam pro pace, arma ac tela pro bello (toga em referência à paz, arma e lança à guerra). ${ }^{70} \mathrm{Na}$ poesia, observamos este uso no verso inicial da Eneida: Arma nirumque cano (Eu canto as armas e o varão). ${ }^{71}$ Sérvio comenta que o uso de arma nessa passagem pode ser visto como metonímia, como o instrumento de guerra em referência à guerra:

\footnotetext{
per 'arma' autem bellum significat, et est tropus metonymia. (1.1.5) nam arma quibus in bello utimur pro bello posuit, sicut toga qua in pace utimur pro pace ponitur, ut Cicero "cedant arma togae", ${ }^{72}$ id est bellum paci". ${ }^{73}$
}

\footnotetext{
${ }^{64}$ Virg., Aen. 2.265.

${ }^{65}$ Quint., Inst. Or. 8.6.24.

${ }^{66}$ Cic., De Or. 3.168.

${ }^{67}$ Quint., Inst. Or. 8.6.26.

${ }^{68}$ Lausberg (2004, p. 161).

${ }^{69}$ Quint., Inst. Or. 8.6.26.

${ }^{70}$ Cic., De Or. 3.167.

${ }^{71}$ Virg., Aen. 1.1.

${ }^{72}$ Cic., In Pisonem 72; De Officiis 1.77; Pbilippicae 2.20.

${ }^{73}$ Sérvio (1878-1884), Commentarii in Vergilii Aeneidos libros 1.1.
} 
Pela "arma", no entanto, refere-se à guerra, e isto consiste no tropo de metonímia. (1.1.5) Pois a arma que usamos na guerra substitui a guerra, assim como a toga que usamos em tempos de paz é utilizada em vez de paz, como diz Cícero "que as armas cedam à toga”, isto é, a guerra à paz.

\section{A metonímia e suas Relações Com outros tropos e figuras}

Nesta passagem do Orator, Cícero considera relações entre a metonímia, a metáfora, a alegoria e a catacrese:

Tralata dico, ut saepe iam, quae per similitudinem ab alia re aut suavitatis aut inopiae causa transferuntur; mutata, in quibus pro verbo proprio subicitur aliud quod idem (93.1) significet sumptum ex re aliqua consequenti. Quod (93.2) quanquam transferundo fit, tamen alio modo transtulit cum dixit Ennius arce et urbe orbam, alio modo, si pro patria arcem dixisset, et horridam Africam terribili (93.5) tremere tumultu cum

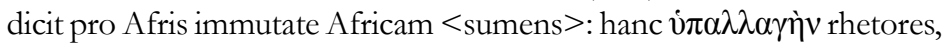
quia quasi summutantur verba pro verbis, $\mu \varepsilon \tau \omega v v \mu i^{\alpha} \alpha v$ (94.1) grammatici vocant, quod nomina transferuntur. Aristoteles autem tralationi et haec

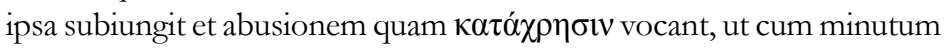
dicimus animum pro parvo; et abutimur verbis pro pinquis, (94.5) si opus est vel quod delectat vel quod decet. iam cum fluxerunt continuae plures tralationes, alia plane fit oratio; itaque genus hoc Graeci appellant $\dot{\alpha} \lambda \lambda \eta \gamma$ opíav: nomine recte, genere melius ille qui ista omnia tralationes vocat. haec frequentat Phalereus (94.10) maxume suntque dulcissima, et quanquam tralatio est apud eum multa tamen immutationes nusquam (95.1) crebriores. $^{74}$

Como eu costumo dizer, chamo metafóricas aquelas [palavras] que, por sua similitude com outra coisa, são empregadas em razão da suavidade ou por necessidade ${ }^{75}$; e metonímicas aquelas em que se substitui o termo próprio por outra palavra com o mesmo sentido, (93.1) depreendido a partir de algo resultante. Pois, embora nesta também ocorra uma transferência, Ênio a empregou de um modo quando disse: tornastes órfãs a cidade e cidadela, e a teria utilizado de outro modo se dissesse cidadela para referir-se à pátria, ou quando diz que a selvagem África treme (93.5) com terrível tumulto, em que África substitui os africanos: a esta, os rétores denominam hipálage, porque uma palavra é substituída por outra; enquanto os gramáticos a chamam de metonímia, (94.1) porque nomes são transladados. Mas Aristóteles atrela todas essas à

\footnotetext{
${ }^{74}$ Cic., Or. 92-95.

${ }^{75}$ Mais especificamente, inópia ou pobreza do sistema linguístico, a falta de um termo próprio; cf. Lausberg (2004, p. 145).
}

Classica, v. 31, n. 1, p. 89-110, 2018 
metáfora, bem como a abusio, chamada catacrese, que ocorre quando dizemos mente diminuta em vez de pequena, e desviamos do uso normal palavras próximas em sentido, (94.5) se for necessário, ou porque deleita, ou porque convém. Já, quando sucederem-se ininterruptamente muitas translações, o discurso transforma-se totalmente. Assim, a esse gênero, os gregos chamam alegoria: apesar de acertado quanto ao nome, quanto ao gênero, está mais correto quem chama a todas estas de metáforas. Demétrio de Falero as utiliza com frequência, (94.10) e elas são extremamente agradáveis, e embora ele faça largo uso de metáforas, ninguém é mais assíduo que ele no emprego de (95.1) metonímias.

\subsection{Metonímia, MEtÁfora E ALEgoria}

De acordo com Cícero, a metonímia se aproxima da metáfora, uma vez que em ambas, de certo modo, ocorre uma translação. ${ }^{76}$ Embora muito próximas, elas diferenciam-se em alguns aspectos. Na passagem do Orator mencionada acima, Cícero propõe uma distinção entre o que ele chama de uerba tralata (ou translata), a metáfora propriamente dita, e uerba mutata (ou immutata), as palavras de caráter metonímico. ${ }^{77}$ Cícero explica que na metonímia, na substituição de um nome por outro, uma palavra não é inventada e nem transladada como nas metáforas, mas modificada em razão do ornato. ${ }^{78}$ Enquanto a metáfora consiste em transladar um tema em razão da similitude, a metonímia (immutatio) opera por contiguidade e consiste em colocar no lugar de um nome uma palavra cujo sentido seja depreendido a partir de algo próximo ou resultante (res consequens). ${ }^{79} \mathrm{~A}$ despeito dessas distinções, se retrocedermos a Aristóteles, veremos que o processo de substituição por contiguidade também é chamado de metáfora.

Como observa Anderson, Aristóteles geralmente trata o termo metáfora em seu sentido literal - transferência - mais especificamente, qualquer transferência de sentido que ocorra em verbo, nome ou frase. ${ }^{80}$ Aristóteles ensina que na metáfora ocorre transferência de nome alheio ou estranho, seja nas relações entre gênero-espécie, espécie-gênero, ${ }^{81}$ espécieespécie ou por analogia: ${ }^{22}$

A metáfora consiste no transportar para uma coisa o nome de outra, ou do gênero para a espécie, ou da espécie para o gênero, ou da espécie de uma para a espécie de outra, ou por analogia. ${ }^{83}$

\footnotetext{
${ }^{76}$ Cíc., De Or. 3.170.

${ }^{77}$ Sobre a distinção entre uerba translata e uerba immutata, cf. Cic., Or. 92-93; Lausberg (2003, Tomo II, 71).

${ }^{78}$ Cíc., De Or. 3.167.

${ }^{79}$ Cic., Or. 92: res consequens.

${ }^{80}$ Anderson (2000, p. 73).

${ }^{81}$ Para a relação espécie-gênero como sinédoque, cf. Quint., Inst. Or. 8.6.19.

${ }^{82}$ Sobre a relação entre metáfora e metonímia em Aristóteles, cf. Al-Sharafi (2000, p. 12-14).

${ }^{83}$ Aristóteles, Po. 1457b. Tradução de Eudoro de Souza.
} 
Ainda segundo Aristóteles, na metáfora proveniente da analogia, é necessária uma correspondência entre termos do mesmo gênero, por exemplo dizer "a taça de Ares" para o "escudo", ou "o escudo de Dioniso" para "taça":

É necessário, por seu turno, que a metáfora, proveniente da analogia, tenha sempre uma correspondência entre dois termos do mesmo gênero. Assim, por exemplo, se a taça é o "escudo de Dioniso", então é apropriado chamar "taça de Ares" ao escudo. ${ }^{84}$

Nessas metáforas, podemos considerar que subjazem relações metonímicas de conteúdo-continente (taça-vinho), símbolo-fenômeno social (escudo-guerra), instrumentopossessor (taça-Dioniso, escudo-Ares) e inventor-invenção (Dioniso-taça-vinho; Aresescudo-guerra)..$^{85}$

A metáfora, como tropo de salto, aproxima-se do símile, mas se dá de maneira mais rápida e direta, sem o termo de comparação. ${ }^{86}$ Por outro lado, a metáfora, como sugere Lausberg, pode ser observada como uma metonímia de "valor mágico" (sentido primitivo religioso da palavra assimilado ao jogo poético), uma vez que reside no fundamento da denominação metafórica uma participação real (vale lembrar que, na metonímia, a alteração se dá com o uso de palavras que implicam uma relação de contiguidade ligadas a fenômenos da realidade, como causa-efeito e as demais espécies a que nos referimos anteriormente), pois, quando se diz que Aquiles, como guerreiro, é um leão, é como se ele realmente assumisse a natureza de um leão (símbolo de coragem e ferocidade). ${ }^{87}$ Nesse sentido, há um parentesco entre a metáfora e a homonímia. ${ }^{88}$ De fato, a palavra metafórica tem mais de um significado, e, se perdesse esse significado secundário, latente, deixaria de ser metáfora. O que ocorre é uma triangulação, uma superposição de significados, um acréscimo referido impropriamente.

De mesmo modo, segundo Arata, uma definição de metonímia fornecida por Trifão dá conta do sentido de metonímia como sinonímia gerada a partir de uma homonímia. ${ }^{89}$ Trifão

\footnotetext{
${ }^{84}$ Arist., Ret. 3.1407a. Tradução de Manuel Alexandre Júnior. Também em Arist., Po. 1457b.: Digo que há analogia quando o segundo termo está para o primeiro na igual relação em que está o quarto para o terceiro, porque, neste caso, o quarto termo poderá substituir o segundo, e o segundo, o quarto. E algumas vezes os poetas ajuntam o termo ao qual se refere a palavra substituída pela metáfora. Por exemplo, a "urna” está para "Dioniso", como o "escudo" para "Ares", e assim se dirá a urna "escudo de Dioniso", e o escudo, "urna de Ares". Tradução de Eudoro de Sousa.

${ }^{85}$ Para as relações metonímicas nessa passagem, cf. Al-Sharafi (2004, 13-14).

${ }^{86}$ Para a relação entre metáfora e símile, cf.: Arist., Ret. 3.1406b; Quint., Inst. Or. 8.6.8-9.

${ }^{87}$ Para o "valor mágico" da metáfora, cf. Lausberg (2003, Tomo II, p. 62). Para a metáfora como metonímia de "valor mágico", cf. Lausberg (2004, p. 162).

${ }^{88}$ Para a definição de homonímia e sua relação com a ambiguidade, cf. Anderson (2000, p. 82); Quint., Inst. Or. 7.9.2: Singula adferunt errorem cum pluribus rebus aut hominibus eadem appellatio est (o $\mu \omega v$ uí $\alpha$ dicitur), ut 'gallus' auem an gentem an nomen an fortunam corporis significet incertum est, et 'Aiax' Telamonius an Oïlei filius. ${ }^{89}$ Arata (2005, p. 57).
}

Classica, v. 31, n. 1, p. 89-110, 2018 
menciona como exemplo o uso de Hefesto para significar fogo. ${ }^{90} \mathrm{O}$ significante Hefesto divide-se em dois sentidos diferentes, de um lado, o sentido próprio é preservado: Hefesto, o deus; de outro lado, com a transposição da metonímia (decorrente da relação inventorinvenção: Hefesto é considerado o inventor do fogo), um novo sentido é criado: Hefesto, o fogo. Assim, de acordo com Arata, a definição dada por Trifão mostra a transição entre a homonímia e o resultado: uma sinonímia secundária entre Hefesto e fogo.

Lausberg observa que a metonímia, assim como a metáfora, pode ser alargada até a alegoria. ${ }^{91}$ É o que ocorre sobretudo com a "metonímia mitológica" (uso dos nomes dos deuses na relação inventor-invenção), que, segundo Lausberg, tem um claro selo metafórico, como na passagem de Terêncio, citada por vários autores: sine Cerere et Libero friget Venus (Sem Ceres e Líber, Vênus é fria), ${ }^{92}$ que é construída alegoricamente com friget. O mesmo ocorre na passagem da Eneida: fert... et commixtam Volcanus ad astra fauillam (Vulcano lança fagulhas misturadas às estrelas), em que Vulcano aparece em construção alegórica com fert. ${ }^{93}$

\subsection{Metonímia e Catacrese}

A catacrese, denominada abusio em latim, consiste em "fossilizar" pelo uso uma construção estranha que reivindica propriedade. ${ }^{94}$ Ela também aparece como tropo compósito, atrelando-se à metonímia e à metáfora. Desse modo, ela pode ser considerada uma espécie de metáfora ou metonímia que atende às necessidades do uso, empregada para preencher uma inópia ou lacuna na linguagem, isto é, quando não há um termo próprio para designar algo. Pelo uso contínuo, determinados termos incorporam-se à língua, deixando de causar estranheza. Quintiliano cita algumas metonímias assimiladas pelo uso: bene moratas urbes (cidades de bons costumes), poculum epotum (beber um copo inteiro), saeculum felix (século feliz), praecipitem iram (precipitada ira), hilarem adolescentiam (alegre adolescência) e segne otium (ócio preguiçoso). ${ }^{95} \mathrm{O}$ exemplo minutum dicimus animum pro parvo (mente diminuta em vez de pequena) é mencionado em duas passagens diferentes de Cícero, o que mostra quanto a metonímia e a catacrese se aproximam e se confundem..${ }^{96}$ No Orator, tal exemplo está ligado

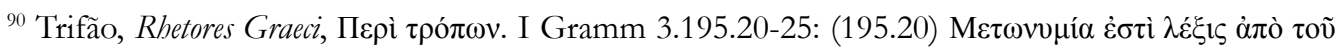

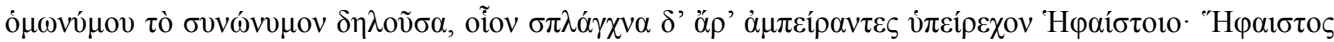

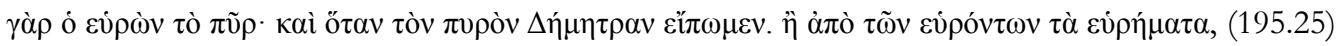

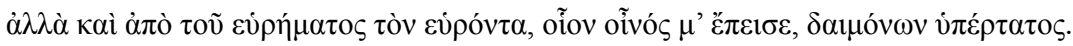

${ }^{91}$ Para as relações entre a metáfora e a alegoria de acordo com os rétores e gramáticos gregos e latinos, cf. Lausberg (2003, Tomo II, p. 71) e (2004, p. 162); Martinho (2008, p. 259-262).

${ }^{92}$ Ter., Eun. 732; Cíc., N. D. 2.60-61; Donato, De tropis, p. 1776 P.; Isid., Orig. 1.37.9; Sérvio, Commentarii in Vergilii Aeneidos libros 1.686.1.

${ }^{93}$ Virg., Aen. 9.75-6; Isid., Orig. 1.37.9: em construção com “mittit”. Para outros exemplos dessa espécie de metonímia, cf. Lausberg (2003, Tomo II, p. 71-72)

${ }^{94}$ Para a catacrese como abusio, cf. Cic., Or. 94.1.

${ }^{95}$ Quint., Inst. Or. 8.6.24-27.

${ }^{96}$ Sobre catacrese e metonímia, cf. Lausberg (2003, Tomo II, p. 78-79).
}

Classica, v. 31, n. 1, p. 89-110, 2018 
à explicação de catacrese e à conveniência ou necessidade de usar tais expressões. ${ }^{97}$ No $D e$ Oratore, o mesmo exemplo é citado em uma explicação sobre o uso da metonímia. ${ }^{98}$

\subsection{Metonímia e Sinédoque}

Como diz Quintiliano, a sinédoque não se distancia da metonímia. ${ }^{99}$ Lausberg explica que a sinédoque pode ser considerada como "uma metonímia de relação quantitativa entre a palavra empregada e o significado sugerido". ${ }^{100}$ Os limites entre a metonímia e a sinédoque se confundem especialmente no que concerne às transposições de sentido obtidas a partir das relações entre parte-todo, gênero-espécie e numérica. ${ }^{101}$ Para Quintiliano, as relações pars-totus (parte-todo), uno-pluris (singular-plural), species-genus (espécie-gênero), praecedenssequentia (precedentes-posteriores) são chamadas de sinédoque. ${ }^{102}$ Quintiliano exemplifica com a seguinte frase a modificação no número, ao considerá-la como sinédoque: Romanus proelio victor (Romano vencedor na batalha), em que o singular romanus dá a entender que os romanos venceram. ${ }^{103}$ Por outro lado, Cícero, como vimos, não estabelece uma distinção clara entre metonímia e sinédoque, referindo-se apenas a determinada figura próxima da metonímia, que deduzimos, a partir dos exemplos, tratar-se da sinédoque, ao citar em sua explicação exemplos das relações parte-todo: pro aedificiis cum parietes aut tecta dicimus (quando dizemos paredes e teto para nos referirmos à casa); e de número: cum unam turmam equitatum populi Romani dicimus (quando dizemos a cavalaria romana em referência a um batalhão). ${ }^{104}$ A alteração no número, além de ser considerada como metonímia ou sinédoque, também aparece como uma figura que recebe o nome de silepse ou enálage. ${ }^{105}$

Porfírio também entende como metonímia o que alguns autores chamam de sinédoque. Em seu comentário desta passagem das Epistolas de Horácio: quattuor aut pluris aulaea premuntur in horas (Por quatro horas ou mais as cortinas se mantêm abaixadas), ${ }^{106}$ Porfírio indica o uso da expressão aulaea premuntur como uma metonímia. ${ }^{107}$ Neste caso, observamos a relação parte-todo: a cortina, parte do espetáculo, está pelo espetáculo (a comédia). Com o uso dessa expressão, Horácio dá a entender que o espetáculo continua, porque nos teatros antigos a cortina era baixada no início da apresentação e elevada ao final.

\footnotetext{
${ }^{97}$ Cic., Or. 93.

${ }^{98}$ Cic., De Or. 3.169.

${ }^{99}$ Quint., Inst. Or. 8.6.23.

${ }^{100}$ Lausberg (2003, Tomo II, p. 76).

${ }^{101}$ Para a sinédoque e metonímia, cf. Lausberg (2003, Tomo II, p. 76-78).

${ }^{102}$ Quint., Inst. Or. 8.6.19.

${ }^{103}$ Quint., Inst. Or. 8.6.21.

${ }^{104}$ Cic., De Or. 3.168.

${ }^{105}$ Para a metonímia e silepse, cf. Lausberg (2003, Tomo II, p. 78).

${ }^{106}$ Hor., Ep. 2.1.189.

${ }^{107}$ Porfírio, Commentum in Horati Epistulas 2.1.189.2: AVLEA. Per aulea [m] comoediam signif(icat). Tropos metonymia (AVLEA. Por "cortina” dá a entender a comédia". Tropo por metonímia).
}

Classica, v. 31, n. 1, p. 89-110, 2018 


\subsection{Metonímia, hipálage E Metalepse}

Cícero aproxima a hipálage da metonímia. ${ }^{108}$ De modo mais específico, a hipálage consiste na alteração gramatical e semântica da relação de um adjetivo: o adjetivo não é relacionado gramaticalmente ao substantivo a que deveria estar ligado, mas a outro. Aparece em construções adjetivas, em que se atribui a alguém ou algo uma qualidade ou ação pertencente a um outro elemento expresso ou subentendido na frase, como em: "ruído domingueiro" de saias engomadas (saias domingueiras) e "medos perigosos" (medo do perigo). ${ }^{109} \mathrm{Um}$ outro elemento pode ficar subentendido na frase, mais especificamente, a relação de causa e efeito característica da metonímia, como nos exemplos citados na Retórica a Herênio: desidiosam artem dicimus, quia desidiosos facit, et frigus pigrum, quia pigros efficit (dizemos que uma arte é ociosa, porque ela torna as pessoas ociosas, ou que o frio é preguiçoso, porque ele causa preguiça). ${ }^{110}$ Quintiliano explica que se diz pallida mors (pálida morte) ${ }^{111}$ porque a morte causa a palidez. Do mesmo modo, também se diz: praecipitem iram, hilarem adulescentiam, segne otium (precipitada ira, alegre adolescência e ócio preguiçoso). ${ }^{112} \mathrm{Em}$ suma, são pares de adjetivos e substantivos em relação de causa e efeito. Nesse sentido, Quintiliano dá exemplos que ligam a metonímia ao epíteto, como quando Virgílio diz: tristis senectus (triste velhice) ${ }^{113}$, mesmo exemplo citado como metonímia. ${ }^{114}$

Lausberg explica que quando a causa é formada por coisa, em função adjetiva, a metonímia está estreitamente ligada à metalepse. ${ }^{115} \mathrm{~A}$ metalepse consiste em uma transição entre tropos, um salto, em que pelos antecedentes se faz conhecer os consequentes ou viceversa. A metalepse é um tropo que procura o estranhamento, fora do contexto, por exemplo, a passagem da Eneida citada como metonímia por Isidoro de Sevilha: ${ }^{116}$ spumantia frena, ${ }^{117}$ em que se diz "freios espumantes" devido à saliva do cavalo que os molha.

\section{Conclusão}

Sem dúvida, há mais a ser investigado sobre a metonímia, não só pela riqueza do corpus de textos antigos sobre o tema, dos quais selecionamos algumas passagens para este

\footnotetext{
${ }^{108}$ Para a hipálage: Cic., Or. 93; Quint., Inst. Or. 8.6.23; Isid., Orig. 1.36 .22 e Lausberg (2004, p. 196). ${ }^{109}$ Eça de Queirós, Primo Basílio.

${ }^{110}$ Her. 4.4.3.

${ }^{111}$ Hor., C. 1.4.13.

${ }^{112}$ Quint., Inst. Or. 8.6.27.

${ }^{113}$ Virg., G. 3.67; Aen. 6.275.

${ }^{114}$ Quint., Inst. Or. 8.6.27; 8.6.41: Et solet fieri aliis adiunctis [epitheton] tropis, ut apud Vergilium 'turpis egestas' et 'tristis senectus'. (E [o epíteto] geralmente se torna um tropo quando se adiciona algo a ele, como quando Virgílio diz: "desonrosa pobreza" e "triste velhice").

115 Para a relação entre a metonímia e a metalepse, cf. Lausberg (2004, p. 160; 2003, Tomo II, p. 75-76). Para a definição de metalepse, Quint., Inst. Or. 8.6.37.

${ }^{116}$ Isid., Orig. 1.37.10.

${ }^{117}$ Virg., Aen. 5.817.
}

Classica, v. 31, n. 1, p. 89-110, 2018 
estudo, mas pelas infindáveis relações que se pode fazer entre este tropo (ou figura) e outras formas de immutatio. No sentido da metonímia como immutatio está sempre presente a ideia de mudança dentro de uma relação de contiguidade, das quais observamos as principais possibilidades. Confrontamos as definições dos rétores e gramáticos, que têm em comum a ideia de substituição de nomes, e cujos exemplos citados dão conta de revelar a complexidade das diferentes espécies e o seu parentesco com outros tropos e figuras. Procurou-se, assim, demonstrar essas relações e também quão tênues são os limites que separam a metonímia de outros tropos, principalmente da metáfora, da sinédoque e da catacrese.

\section{REFERÊNCIAS}

AL-SHAFARI, A. G. M. Towards a textual theory of metonymy: a semiotic approach to the nature and role of metonymy in text. Basingstoke: Palgrave Macmillan, 2004.

ANDERSON Jr., R. D. Glossary of Rhetorical Terms Connected to Methods of Argumentation, Figures and Tropes from Anaximenes to Quintilian. Leuven: Peeters, 2000.

ARATA, L. The definition of metonymy in Ancient Greece. Style, v. 39, n. 1, p. 55-71, 2005.

ARISTÓTELES. Retórica. Prefácio e introdução de Manuel Alexandre Júnior. Tradução e notas de Manuel Alexandre Júnior, Paulo Farmhouse Alberto e Abel do Nascimento Pena. Lisboa: Imprensa Nacional Casa da Moeda, 2005.

ARISTÓTELES. Poética. Tradução de Eudoro de Sousa. In: Os Pensadores. São Paulo: Abril Cultural, 1973.

CICERO. De Oratore. Book III. De Fato. Paradoxa Stoicorum. De Partitione Oratoria. With an English Translation by H. Rackam. Cambridge: Harvard University Press, 1948.

CICERO. Orator. M. Tulli Ciceronis Scripta Quae Manserunt Omnia. P. Reis (Ed.). Fasc. 5. Leipzig: Teubner, 1932.

[CICERO] 1999. Rhetorica Ad Herennium. With an English Translation by Harry Caplan. Cambridge: Harvard University Press, 1999.

CICERO. Rhetorica ad Herennium [sp.]. M. Tulli Ciceronis. Scripta Quae Manserunt Omnia. Fasc. 1. F. Marx (Ed.), 1923.

FESTUS. Sextus Pompeius. De Verborum Significatione (Sexti Pompei Festi De Verborum Significatu Quae Supersunt cum Pauli Epitome. W. M. Lindsay (Ed.). Leipzig, 1913.

HORACE. Odes and Epodes. Ed. and Transl. by Niall Rudd. Cambridge: Harvard University Press, 2004.

HORACE. Satires, Epistles, Ars Poetica. With an English Translation by H. Rushton Fairclough. Cambridge: Harvard University Press, 1942. 
HORACE. Epistles. Book I. Cambridge Greek and Latin Classics. Edited by Roland Mayer. Cambridge: Cambridge University Press, 1994.

ISIDORE OF SEVILLE. The Etymologies of Isidore of Seville. Stephen A. Barney; W. J. Lewis, J. A. Beach, Oliver Berghof. With the collaboration of Muriel Hall. Cambridge: Cambridge University Press, 2006.

KEIL, H; MOMMSEN, Th. (Ed.). Grammatici Latini. v. 4: Probi, Donati, Servii qui feruntur de arte grammatica libri, et Notarum laterculi. Cambridge: Cambridge University Press, 2009.

LAUSBERG, H. Elementos de Retórica Literária. Lisboa: Fundação Calouste Gulbekian, 2004.

LAUSBERG, H. Manual de Retórica Literaria. Tomos I e II. Fundamentos de una ciencia de la literatura. Version Espanõla de José Pérez Riesco. Biblioteca Románica Hispánica. Madrid: Editorial Gredos, 2003.

MARTINHO, M. A definição de alegoria segundo os gramáticos e rétores gregos e latinos. Classica, n. 21, p. 252-264, 2008.

POMPONIUS PORPHYRIO. Commentum in Horati Epistula. In: HOLDER, A. (Ed.). Pomponi Porfyrionis Commentum in Horatium Flaccum. New York: Arno Press, 1894.

QUINTILIAN. Institutio Oratoria VII-IX. With an English Translation by H. E. Butler. Cambridge: Harvard University Press, 1996.

SERVIUS HONORATUS. Maurus Servius Honoratus. In: THILO, G. (Ed.). Vergilii Aeneidos Libros. Servii Grammatici Qui Feruntur in Vergilii Carmina Commentarii. 1878-1884. v. 1-2.

P. VERGILIS MARONIS Opera. Aeneis. R. A. B. Mynors (Ed.). Oxford: Oxford University Press, 1972. 